\title{
Malformations in a cohort of 284 women with Mayer-Rokitansky-Küster-Hauser syndrome (MRKH)
}

\author{
Patricia G Oppelt ${ }^{1 \dagger}$, Johannes Lermann ${ }^{1 \dagger}$, Reiner Strick ${ }^{1}$, Ralf Dittrich ${ }^{1}$, Pamela Strissel ${ }^{1}$, Ingo Rettig ${ }^{2}$, \\ Christine Schulze ${ }^{1}$, Stefan P Renner ${ }^{1}$, Matthias W Beckmann¹, Sara Brucker ${ }^{3}$, Katharina Rall ${ }^{3+}$ and Andreas Mueller ${ }^{1^{*+}}$
}

\begin{abstract}
Background: The aim of this retrospective study was to describe the spectrum of genital and associated malformations in women with Mayer-Rokitansky-Küster-Hauser syndrome using evaluated diagnostic procedures and the Vagina Cervix Uterus Adnex - associated Malformation classification system (VCUAM).

Methods: 290 women with MRKH syndrome were clinically evaluated with using clinical examinations, abdominal and perineal/rectal ultrasound, MRI, and laparoscopy.

Results: Classification of female genital malformation according to the Vagina Cervix Uterus Adnex - associated Malformation classification system was possible in 284 women (97.9\%). Complete atresia of Vagina (V5b) and bilateral atresia of Cervix (C2b) were found in 284 patients (100\%). Uterus: bilateral rudimentary or a plastic uterine horns were found in 239 women (84.2\%). Adnexa: normal Adnexa were found in 248 women (87.3\%).

Malformations: associated malformations were found in 126 of 282 evaluable women (44.7\%), 84 women (29.6\%) had malformations of the renal system. Of 284 women with Mayer-Rokitansky-Küster-Hauser syndrome 212 women (74.7\%) could be classified as V5bC2bU4bA0. The most frequent classification was V5bC2bU4bA0M0 (46.8\%) diagnosed in 133 of 284 women.

Conclusions: Complete atresia of vagina and cervix were found in all patients, variable malformations were found with uterus and adnexa. A variety of associated malformations were present, predominantly of the renal system. It is therefore recommended that all patients with genital malformations should be evaluated for renal abnormalities.
\end{abstract}

Keywords: MRKH syndrome, Diagnosis, Staging, Malformations, VCUAM, Renal abnormalities

\section{Background}

The Mayer-Rokitansky-Küster-Hauser (MRKH) syndrome describes women with normal female external development and internally with normally regressed mesonephric (Wolffian) ducts, but abnormally absent paramesonephric (Müllerian) ducts. MRKH syndrome involves congenital aplasia of the uterus, cervix and upper two-thirds of the vagina. The syndrome is only revealed when primary amenorrhea is noticed or attempts at coitus are in vain. It occurs as a purely genital malformation

\footnotetext{
* Correspondence: andreas.mueller@uk-erlangen.de

${ }^{\dagger}$ Equal contributors

'Department of Obstetrics and Gynecology, Erlangen University Hospital, Universitätsstrasse 21-23, Erlangen 91054, Germany

Full list of author information is available at the end of the article
}

(type 1), but also with associated malformations (type 2 and MURCS association; Müllerian renal, cervicothoracic somite abnormalities) [1]. Malformations of the kidneys and urinary tract the skeleton, and more rarely of the heart and central nervous system have been described [2]. The incidence of the syndrome is one in 4,500 female newborns [1]. A failure of fusion of Müllerian duct derivatives during gestational weeks 4-12 results in malformation of the vagina and uterus [3]. However, the precise pathogenetic mechanism is still unknown. MRKH patients have a correctly timed pubarche and thelarche and have a normal female karyotype (46, XX) [3]. The syndrome was first described by Mayer [4] in 1829, and Rokitansky [5] later published a case report on similar malformations. In 1910, Küster wrote the first review on the syndrome [6].

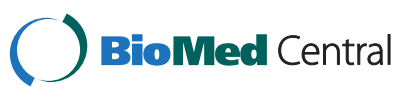


Table 1 VCUAM classification [8]

\begin{tabular}{|c|c|c|}
\hline Organ & Stage & Description \\
\hline \multirow[t]{15}{*}{ Vagina $(V)$} & 0 & Normal \\
\hline & $1 a$ & Partial hymenal atresia \\
\hline & $1 b$ & Complete hymenal atresia \\
\hline & $2 a$ & Incomplete septate vagina $<50 \%$ \\
\hline & $2 b$ & Complete septate vagina \\
\hline & 3 & Stenosis of the introitus \\
\hline & 4 & Hypoplasia \\
\hline & $5 a$ & Unilateral atresia \\
\hline & $5 b$ & Complete atresia \\
\hline & S1 & Sinus urogenitalis (deep confluence) \\
\hline & S2 & Sinus urogenitalis (middle confluence) \\
\hline & S3 & Sinus urogenitalis (high confluence) \\
\hline & C & Cloacae \\
\hline & + & Other \\
\hline & \# & Unknown \\
\hline \multirow[t]{6}{*}{ Cervix (C) } & 0 & Normal \\
\hline & 1 & Duplex cervix \\
\hline & $2 a$ & Unilateral atresia/aplasia \\
\hline & $2 b$ & Bilateral atresia/aplasia \\
\hline & + & Other \\
\hline & \# & Unknown \\
\hline \multirow[t]{10}{*}{ Uterus (U) } & 0 & Normal \\
\hline & $1 a$ & Arcuate \\
\hline & $1 b$ & Septate $<50 \%$ of the uterine cavity \\
\hline & $1 c$ & Septate $>50 \%$ of the uterine cavity \\
\hline & 2 & Bicornate \\
\hline & 3 & Hypoplastic uterus \\
\hline & $4 a$ & Unilaterally rudimentary or aplastic \\
\hline & $4 b$ & Bilaterally rudimentary or aplastic \\
\hline & + & Other \\
\hline & \# & Unknown \\
\hline \multirow[t]{9}{*}{ Adnexa $(A)$} & 0 & Normal \\
\hline & $1 a$ & $\begin{array}{l}\text { Unilateral tubal malformation, ovaries } \\
\text { normal }\end{array}$ \\
\hline & $1 b$ & $\begin{array}{l}\text { Bilateral tubal malformation, ovaries } \\
\text { normal }\end{array}$ \\
\hline & $2 a$ & $\begin{array}{l}\text { Unilateral hypoplasia/gonadal streak } \\
\text { (includingtubal malformation if } \\
\text { appropriate) }\end{array}$ \\
\hline & $2 b$ & $\begin{array}{l}\text { Bilateral hypoplasia/gonadal streak } \\
\text { (includingtubal malformation if } \\
\text { appropriate) }\end{array}$ \\
\hline & $3 a$ & Unilateral aplasia \\
\hline & $3 b$ & Bilateral aplasia \\
\hline & + & Other \\
\hline & \# & Unknown \\
\hline
\end{tabular}

Table 1 VCUAM classification [8] (Continued)

\begin{tabular}{lll}
\hline $\begin{array}{l}\text { Associated } \\
\text { malformations (M) }\end{array}$ & O & None \\
& R & Renal system \\
S & Skeleton \\
C & Cardiac \\
N & Neurologic \\
& + & Other \\
& $\#$ & Unknown \\
\hline
\end{tabular}

Hauser and Schreiner were the first in 1961 to call it Mayer-Küster-Rokitansky syndrome [7]. The final addition of Hauser to the name resulted in today's term, Mayer-Rokitansky-Küster-Hauser syndrome.

The Vagina, Cervix, Uterus, $A$ dnex - associated Malformation (VCUAM) classification (Table 1) was introduced in 2005 to allow an accurate description of genital and associated malformations [8-11].

Clinical examination, ultrasound, magnetic resonance imaging (MRI), and laparoscopy can help to diagnose MRKH syndrome $[9,12-16]$. We recently presented a comparison of different diagnostic procedures for the correct staging of the malformations according to the VCUAM classification with defined reference methods for the different organs involved in the syndrome. The reference methods were: vagina - clinical examination; cervix/uterus and adnexa - laparoscopy; urinary tract malformations - MRI [17]. The quality of other diagnostic procedures for each organ was expressed as agreement with the reference methods, which was presented as kappa value $(k)$. For vagina and cervix only clinical examination was found to be sufficient, for uterus MRI ( $k 0.93)$ or ultrasound ( $\mathrm{k} 0.83$ ) were found to be sufficient, for adnexa only laparoscopy was found to be sufficient and for urinary tract malformations ultrasound was also found to be sufficient $(k 0.87)$ [17].

The aim of this study was to describe the spectrum of malformations in a large cohort of 290 women with MRKH syndrome in order to verify the most common subtypes of this syndrome.

\section{Methods}

The study is a two centre retrospective analysis of 290 women who were treated between January 2000 and October 2011 for MRKH syndrome in the University hospitals of Erlangen and Tübingen (Germany).

All patient files were systematically analysed and all data were used anonymously. Each malformation of the organs was classified in accordance with the VCUAM classification $[8,9]$, based upon the results of the reference methods, for vagina - clinical examination, for cervix and adnexa - laparoscopy for uterus - ultrasound and for associated malformations - MRI. In case 
a classification for each organ was not possible using the reference methods other diagnostic procedures with a good agreement with the reference methods $(k>0.80)$ were considered. Vagina: all women received a regular gynecological examination, including rectal palpation. Uterus: ultrasound examinations were performed transabdominally using standard $2-7 \mathrm{MHz}$ probes, or perineally/transrectally using standard $3.3-10 \mathrm{MHz}$ probes in all women. Cervix and adnexa: all women underwent laparoscopy, sometimes as part of a modified laparoscopic Vecchietti operation [18-20]. Malformations: Ultrasound examinations were performed transabdominally using standard 2-7 MHz probes and/or MRI was carried out with a 1.5-T magnetic resonance system in some women. Approval for conducting basic research and compiling the relevant documentation to perform this study was received through Institution review board (IRB) approval No. 3074.

\section{Statistical analysis}

All data are presented as frequencies and percentages using Microsoft Office Excel 2009 and IBM SPSS Statistics 19.

\section{Results}

The patient files of 290 women with MRKH syndrome who were diagnosed and treated during the study period were analysed and 284 files were eligible for inclusion in the analysis. Six patient files were excluded because of missing examination results. All 284 women underwent clinical examination, ultrasound and laparoscopy. A diagnostic laparoscopy and/or therapeutic intervention were performed with 275 women (96.8\%). MRI of the urinary tract was carried out in most women; in addition an MRI was performed for some women to investigate skeletal malformations. Women with skeletal, neuronal or cardiac malformations were further examined, using thorax X-ray, echocardiography, audiometry or visual tests. The mean age of the women at the time of inclusion was 26.2 (SD 8.8) years and the mean body mass index at the time of diagnostic or therapeutic intervention was 23.1 (SD 4.8$) \mathrm{kg} / \mathrm{m}^{2}$.

\section{VCUAM classifications \\ Vagina (V)}

284 women (100\%) showed stage V5b (complete atresia) of the vagina.

\section{Cervix (C)}

284 women $(100 \%)$ showed stage $2 \mathrm{~b}$ (bilateral atresia/ aplasia).

\section{Uterus (U)}

239 women $(84.2 \%)$ showed stage $4 \mathrm{~b}$ (bilateral rudimentary or aplastic), 27 women (9.5\%) showed stage 4a (unilateral rudimentary or aplastic), eight women (2.8\%) showed other and eight women $(2.8 \%)$ were not classifiable. Two women $(0.7 \%)$ showed stage 3 (hypoplastic uterus).

\section{Adnexa ( $A$ )}

248 women $(87.3 \%)$ showed stage 0 (normal adnexa), nine (3.2\%) were not classifiable, ten (3.5\%) showed stage $2 \mathrm{a}$ (unilateral hypoplasia), seven (2.5\%) showed $1 \mathrm{~b}$ (bilateral tubal malformation) and six women (2.1\%) showed stage 3a (unilateral aplasia). Two women $(0.7 \%)$ showed stage $2 \mathrm{~b}$ (bilateral hypoplasia/gonadal streak) and one women $(0.4 \%)$ stage 1a (unilateral tubal malformation). One woman $(0.4 \%)$ showed other malformations.

\section{Malformations (M)}

In 156 women (54.9\%) of 284 women no associated malformations were diagnosed (stage 0). In 53 women (18.7\%) malformations of the renal system (stage R) and in 22 women $(7.7 \%)$ malformations of the skeleton (stage S) were found. Two women (0.7\%) were not classifiable, five $(1.8 \%)$ showed other malformations, two women (0.7\%) showed cardiac malformations and four woman $(1.4 \%)$ showed neurologic malformations. Moreover in 38 women (13.4\%) different combinations (renal, skeleton, cardiac, neurologic, others) were found. Table 2 illustrates associated malformations of 282 women, excluding two women which were not classifiable. Eightyfour patients $(29.6 \%)$ showed renal malformations where two women were excluded because of an unknown renal status (see Table 3). Fifty-three of these 84 patients $(64.4 \%)$ or $18.8 \%$ of all patients with known malformations showed a renal agenesis.

In summary, excluding associated malformations from 284 women with MRKH syndrome, 212 women could be classified as complete atresia of the vagina (V5b), bilateral atresia of the cervix $(\mathrm{C} 2 \mathrm{~b})$, bilateral aplastic uterus (U4b) and normal adnexa (A0) (74.7\%). The most frequent VCUAM classification was V5bC2bU4bA0M0 diagnosed in 133 (46.8\%) of 284 women. The spectrum of associated malformations is shown in Figure 1.

\section{Discussion}

To the best of our knowledge, this study represents the largest cohort of 284 women with MRKH syndrome diagnosed with evaluated and standardized diagnostic procedures and grouped according to a defined classification system. There is a unique occurrence in malformations of the distal genital system; vagina, cervix and uterus. The spectrum of variations accumulates in the more proximal part of the female genital system with a 
Table 2 VCUAM classification of 284 patients with MRKH syndrome

\begin{tabular}{|c|c|c|c|c|c|c|c|c|c|}
\hline Vagina & n (\%) & Cervix & n (\%) & Uterus & n (\%) & Adnexa & n (\%) & Malformation & n (\%) \\
\hline \multirow[t]{21}{*}{$\mathrm{V} 5 \mathrm{~b}$} & $284(100 \%)$ & $\mathrm{c} 2 \mathrm{~b}$ & $284(100 \%)$ & UO & $0(0 \%)$ & $\mathrm{AO}$ & $248(87.3 \%)$ & MO & $156(54.9 \%)$ \\
\hline & & & & U1a & $0(0 \%)$ & Ala & $1(0.4 \%)$ & MR & $53(18.7 \%)$ \\
\hline & & & & U1b & $0(0 \%)$ & $A 1 b$ & $7(2.5 \%)$ & MS & $22(7.7 \%)$ \\
\hline & & & & U1c & $0(0 \%)$ & $\mathrm{A} 2 \mathrm{a}$ & $10(3.5 \%)$ & $M C$ & $2(0.7 \%)$ \\
\hline & & & & U2 & $0(0 \%)$ & $\mathrm{A} 2 \mathrm{~b}$ & $2(0.7 \%)$ & $\mathrm{MN}$ & $4(1.4 \%)$ \\
\hline & & & & U3 & $2(0.7 \%)$ & A3a & $6(2.1 \%)$ & $\mathrm{M}+$ & $5(1.8 \%)$ \\
\hline & & & & U4a & 27 (9.5\%) & $\mathrm{A} 3 \mathrm{~b}$ & $0(0 \%)$ & M\# & $2(0.7 \%)$ \\
\hline & & & & U $4 b$ & 239 (84.2\%) & $A+$ & $1(0.4 \%)$ & Combinations & \\
\hline & & & & $U_{+}$ & $8(2.8 \%)$ & A\# & $9(3.2 \%)$ & MR+ & $3(1.1 \%)$ \\
\hline & & & & U\# & $8(2.8 \%)$ & & & MRC & $1(0.4 \%)$ \\
\hline & & & & & & & & MRC+ & $1(0.4)$ \\
\hline & & & & & & & & MRN & $2(0.7 \%)$ \\
\hline & & & & & & & & MRS & $15(5.3)$ \\
\hline & & & & & & & & MRS+ & $4(1.4 \%)$ \\
\hline & & & & & & & & MRSC & $2(0.7)$ \\
\hline & & & & & & & & MRSN & $3(1.1 \%)$ \\
\hline & & & & & & & & MS+ & $2(0.7 \%)$ \\
\hline & & & & & & & & MSC & $1(0.4)$ \\
\hline & & & & & & & & MSCN & $2(0.7 \%)$ \\
\hline & & & & & & & & MSN & $3(1.1)$ \\
\hline & & & & & & & & $M C+$ & $1(0.4)$ \\
\hline
\end{tabular}

Table 3 Specification of 82 renal malformations diagnosed in 284 patients with MRKH syndrome

\begin{tabular}{ll}
\hline Renal malformations & patients \\
\hline ureter malformation & 2 \\
renal malrotation & 2 \\
pelvic kidney & 8 \\
pelvic kidneys & 1 \\
pelvic kidney + ureter malformation & 1 \\
double renal pelvis & 1 \\
duplex kidney & 5 \\
duplex kidneys & 1 \\
duplex kidney + ureter malformation & 1 \\
cirrhosis of the kidney & 3 \\
horseshoe kidney & 3 \\
horseshoe kidney + ureter malformation + cystic kidney disease & 1 \\
kidney agenesis & 35 \\
kidney agenesis + duplex ureter & 1 \\
kidney agenesis + pelvic kidney & 15 \\
kidney agenesis + pelvic kidney + renal malrotation & 1 \\
kidney agenesis + bladder malformation + persistent urachus & 1 \\
\hline
\end{tabular}

variety of adnexal and associated malformations. Most associated malformations were found in the renal system along with additional numerous combinations of different malformations (see Figure 1).

Examination of women with MRKH syndrome revealed according to the definition of MRKH syndrome an absence or severe hypoplasia of the upper vagina as well as uterine agenesis. In the present study $100 \%$ of MRKH women showed a complete atresia of vagina, although $1-3 \mathrm{~cm}$ of the lower vagina can be present. We found in $100 \%$ of patients an aplasia of the cervix (Table 2). In our study $87.3 \%$ of patients showed normal adnexa (stage A0), ten (3.5\%) showed stage 2a (unilateral hypoplasia), seven (2.5\%) showed $1 \mathrm{~b}$ (bilateral tubal malformation) and six women (2.1\%) showed stage 3a (unilateral aplasia). Two women $(0.7 \%)$ showed stage $2 \mathrm{~b}$ (bilateral hypoplasia/gonadal streak) and one women (0.4\%) stage 1a (unilateral tubal malformation). One woman $(0.4 \%)$ showed other malformations (Table 2). We did not find a tendency toward polycystic ovaries as some authors reported [7,21,22]. We agree with Rokitansky, Bompiani and Oppelt et al. who described hypoplastic or aplastic ovaries only in a few cases $[3,5,23]$. Characteristic for all MRKH patients is the unilateral or bilateral hypoplasia of the uterus. In our study $84.2 \%$ showed bilaterally rudimentary or aplastic uterus, 


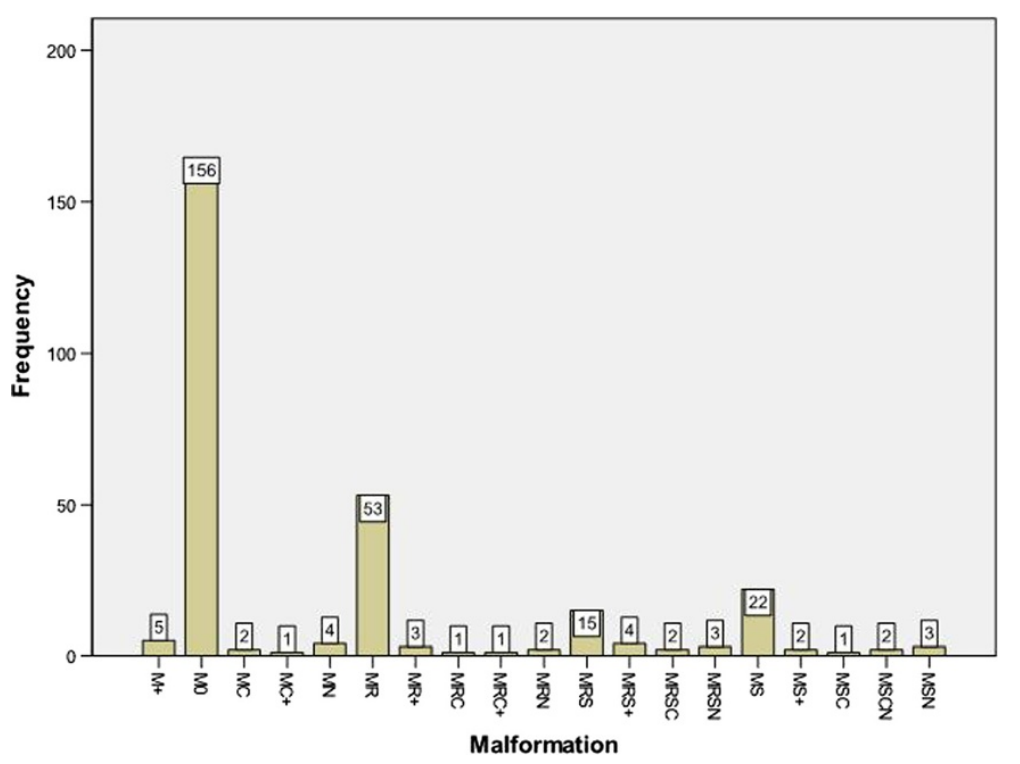

Figure 1 Malformations of 282 patients with $M R K H$ syndrom excluding $M \# . M+=5, M 0=156, M C=2, M C+=1, M N=4, M R=53, M R+=3$, $M R C=1, M R C+=1, M R N=2, M R S=15, M R S+=4, M R S C=2, M R S N=3, M S=22, M S+=2, M S C=1, M S C N=2 ; M S N=3$.

in $9.5 \%$ a unilaterally rudimentary or aplastic uterus was diagnosed. Two (0.7\%) women had a hypoplastic uterus (Table 2). These proportions of the uterus developmental state in MRKH patients was similar to Guerrier et al. [24].

The present analysis showed that $44.4 \%$ of the patients were affected by associated malformations. Excluding women which were not classifiable $(\mathrm{M \# )}(0.7 \%)$, we found associated malformations in $44.7 \%$ of patients (Table 3). The rate of associated malformations in patients with MRKH syndrome reported in the literature was between 53\% [3] and 64\% [25]. Although MRKH patients have a normal female karyotype, in case of severe hormonal alterations, like the androgen insensitivity syndrome, it is recommended that patients should be analysed for chromosomal changes. In our study we focused more on the examination of the renal system, where every woman received an examination by laparoscopy and ultrasound and/or MRI. No direct symptoms of skeletal malformations like dorsal pain, scoliosis etc. excluded MRI analysis. An open inguinal canal was often found during laparoscopy, but only women with an operated inguinal hernia were classified as M+. Malformations of the renal system were seen in up to $32 \%$ of the patients and represented the largest proportion of affected organs [3]. $29.6 \%$ of our cohort (284 patients) had renal malformations, confirming this as the most frequent associated malformation with MRKH (Table 3). The most frequent renal malformation was a renal agenesis (64.4\%).

Furthermore, we support that the associated renal malformations with MRKH can be explained due to the close link between genital and urinary embryonal development.

The human genital tracts are undifferentiated until the 8th week of gestation and are referred to as "bipotential or indifferent" gonads. At this time both the male and female embryo have two symmetrical paired genital ducts: the mesonephric (Wolffian) and the paramesonephric (Müllerian) ducts, which originate from the intermediate mesoderm. Together with the urogenital sinus they provide the bases for internal and external genital development. Only one of the two ductal systems will normally develop further, depending on whether differentiation of a testis or ovary has begun. The distal mesonephric duct is the starting point for a pair of ureteric buds, which grow into the cloaca and induces the overlying metanephros to develop into the primitive kidneys. The ureteric buds and distal portions of the mesonephric ducts are later incorporated into the wall of the primitive bladder to develop into ureters, trigone and bladder neck. In the female embryo, the mesonephric duct regresses completely and the paramesonephric (Müllerian) duct develops into the fallopian tubes, uterus, cervix and upper part of the vagina. Importantly, ovaries originate within the primitive ectoderm, thus are independent of the mesonephros. In the male embryo, testosterone and androstenedione stimulates mesonephric duct development to form the epididymi, vasa deferentia and seminal vesicles, while the Müllerian duct regresses in response to anti-Müllerian-hormone, which is secreted from the Sertoli cells. The disappearance of the Müllerian ducts in the male fetus is completed by 9 to 10 weeks of gestation [26-28]. 
It is interesting to note that in the general population, urinary tract defects occur in as many as 1:100 live births and constitute the most frequent cause of chronic kidney disease in children [29]. Considering the incidence of MRKH in 1:4,500 live female births, congenital renal malformations (as well as unilateral renal agenesis) in MRKH patients are higher compared to the general population. This is not surprising due to the association and interaction of the two ductal systems for normal genital and renal development. Combined urogenital malformations are common with estimations of 10 in 100 cases and account for over 30\% of all congenital malformations [30]. Malformations of the genital and renal axis are common, e.g. $35 \%$ of females where unilateral renal agenesis showed partial or complete duplication of the genital tract [31]; renal agenesis was present in $43 \%$ of patients with uterus didelphys and $10 \%$ of patients with other genital tract abnormalities had an abnormal or ectopic kidney [32]. As a matter of course all patients with genital malformations should be evaluated for renal abnormalities, may be patients with renal abnormalities should also be assessed for genital malformations.

\section{Conclusions}

There is a unique occurrence in malformations of the distal genital system; vagina, cervix and uterus, while the spectrum of variations accumulates in the more proximal part of the female genital system with a variety of adnexal and associated malformations. Those malformations can be classified precisely using evaluated diagnostic procedures and a standardized classification system. It is recommended that all patients with genital malformations should be evaluated for renal abnormalities, but importantly patients with renal abnormalities should also be assessed for genital malformations.

\section{Abbreviations}

A: Adnexa; C: Cervix; IBM: International Business Machines Corporation; IRB: Institution review board; M: Malformations; MRI: Magnetic resonance imaging; MRKH: Mayer-Rokitansky-Küster-Hauser syndrome; MURCS: Müllerian hypoplasia/aplasia, renal agenesis and cervicothoracic somite dysplasia; N: Neurologic; U: Uterus; V: Vagina; R: Renal; S: Skeleton; SD: Standard deviation; SPSS: Statistical Package for the Social,Sciences.

\section{Competing interests}

All of the authors declare that they have no competing interest.

\section{Authors' contributions}

$\mathrm{PGO}, J \mathrm{~L}$ and $\mathrm{AM}$ participated in the design of the study and drafted the manuscript. PS, IR, CS, SPR and KR performed the data collection. RS, RD, $M W B$ and SB controlled the classification of the malformations. RS and RD were responsible for statistical analysis and presentation of the data. $J$ and AM were responsible for the finalizing the manuscript. All authors read and approved the final manuscript.

\section{Acknowledgements}

This work was supported by a grant of the "Deutsche Forschungsgemeinschaft" (DFG) to RS (STR 923/2-2). The authors are grateful for the participation of the patients in this study.

\section{Author details}

1 Department of Obstetrics and Gynecology, Erlangen University Hospital, Universitätsstrasse 21-23, Erlangen 91054, Germany. ${ }^{2}$ Department of Internal Medicine IV, Tübingen University Hospital, Otfried-Müller-Straße 10, Tübingen 72076, Germany. ${ }^{3}$ Department of Obstetrics and Gynecology, Tübingen University Hospital, Calwerstr. 7, Tübingen 72076, Germany.

Received: 3 May 2012 Accepted: 11 August 2012

Published: 20 August 2012

\section{References}

1. Morcel K, Guerrier D, Watrin T, Pellerin I, Leveque J: The Mayer-RokitanskyKuster-Hauser (MRKH) syndrome: clinical description and genetics. J Gynecol Obstet Biol Reprod (Paris) 2008, 37:539-546.

2. Morcel K, Camborieux L, Guerrier D: Mayer-Rokitansky-Kuster-Hauser (MRKH) syndrome. Orphanet J Rare Dis 2007, 2:13.

3. Oppelt P, Renner SP, Kellermann A, Brucker S, Hauser GA, Ludwig KS, Strissel PL, Strick R, Wallwiener D, Beckmann MW: Clinical aspects of MayerRokitansky-Kuester-Hauser syndrome: recommendations for clinical diagnosis and staging. Hum Reprod 2006, 21:792-797.

4. Mayer CAJ: Über Verdopplung des Uterus und ihre Arten, nebst Bemerkungen über Hasenscharte und Wolfsrachen. J Chir Augenheilk 1829, 13:525-564.

5. Rokitansky C: Über die sogenannten Verdopplungen des Uterus. Med Jahrb Öst Staat 1838, 26:39-46.

6. Küster $\mathrm{H}$ : Uterus bipartitus solidus rudimentarius cum vagina solida. $Z$ Geburtshilfe Gynakol 1910, 67:692-718.

7. Hauser GA, Schreiner WE: Mayer-Rokitansky-Kuester syndrome. Rudimentary solid bipartite uterus with solid vagina. Schweiz Med Wochenschr 1961, 91:381-384.

8. Oppelt P, Renner SP, Brucker S, Strissel PL, Strick R, Oppelt PG, Doerr HG, Schott GE, Hucke J, Wallwiener D, Beckmann MW: The VCUAM (Vagina Cervix Uterus Adnex-associated Malformation) classification: a new classification for genital malformations. Fertil Steril 2005, 84:1493-1497.

9. Weibliche genitale Fehlbildungen: A clinical guideline of the Deutsche Gesellschaft für Gynäkologie und Geburtshilfe (DGGG), published on July 2010: 2012. http://www.awmf.org/leitlinien/detail/I//015-052.html.

10. Oppelt $P$, von Have M, Paulsen M, Strissel PL, Strick R, Brucker S, Wallwiener $D$, Beckmann MW: Female genital malformations and their associated abnormalities. Fertil Steril 2007, 87:335-342.

11. Singh G, Sunita V: Double uteri with cervicovaginal agenesis. Fertil Steril 2016, 2008(90):e2013-2015.

12. Feng F, Liu ZF, Pan WD, Meng W, Jin Y, Jin ZY: Magnetic resonance imaging of congenital vaginal anomalies. Zhongguo Yi Xue Ke Xue Yuan Xue Bao 2005, 27:103-107.

13. Strubbe EH, Willemsen WN, Lemmens JA, Thijn CJ, Rolland R: MayerRokitansky-Kuster-Hauser syndrome: distinction between two forms based on excretory urographic, sonographic, and laparoscopic findings. AJR Am J Roentgenol 1993, 160:331-334.

14. Breech LL, Laufer MR: Mullerian anomalies. Obstet Gynecol Clin North Am 2009, 36:47-68.

15. Croak AJ, Gebhart JB, Klingele CJ, Lee RA, Rayburn WF: Therapeutic strategies for vaginal Mullerian agenesis. J Reprod Med 2003, 48:395-401.

16. Buttram VC Jr, Gibbons WE: Mullerian anomalies: a proposed classification. (An analysis of 144 cases). Fertil Steril 1979, 32:40-46.

17. Lermann J, Mueller A, Wiesinger E, Haberle L, Brucker S, Wallwiener D, Dittrich R, Renner SP, Beckmann MW, Oppelt PG: Comparison of different diagnostic procedures for the staging of malformations associated with Mayer-Rokitansky-Kuster-Hauser syndrome. Fertil Steril 2011, 96:156-159.

18. Brucker SY, Gegusch M, Zubke W, Rall K, Gauwerky JF, Wallwiener D: Neovagina creation in vaginal agenesis: development of a new laparoscopic Vecchietti-based procedure and optimized instruments in a prospective comparative interventional study in 101 patients. Fertil Steril 2008, 90:1940-1952.

19. Gauwerky JF, Wallwiener D, Bastert G: An endoscopically assisted technique for construction of a neovagina. Arch Gynecol Obstet 1992, 252:59-63.

20. Vecchietti G: Le néo-vagin dans le syndrome di Rokitansky-Küster-Hauser. Rev Med Suisse Romande 1979, 99:593-601.

21. Gradenwitz: Entfernung der inneren Genitalien bei Fehlen der Scheide. Zentralbl Gynakol 1903, 30:563-564. 
22. Glimm G: Solid, rudimentary pseudo-unicornid uterus with vaginal aplasia an construction of artifical vagina. Zentralbl Gynaekol 1956, 78:1765-1768.

23. Bompiani A, Rigat L: Value of pneumopelvigraphy in the study of uteroovarian dysplasias. CR SoC Fr Gynecol 1958, 28:390-395.

24. Guerrier D, Mouchel T, Pasquier L, Pellerin I: The Mayer-Rokitansky-KusterHauser syndrome (congenital absence of uterus and vagina)-phenotypic manifestations and genetic approaches. J Negat Results Biomed 2006, 5:1.

25. Griffin JE, Edwards C, Madden JD, Harrod MJ, Wilson JD: Congenital absence of the vagina. The Mayer-Rokitansky-Kuster-Hauser syndrome. Ann Intern Med 1976, 85:224-236.

26. Dwyer PL, Rosamilia A: Congenital urogenital anomalies that are associated with the persistence of Gartner's duct: a review. Am J Obstet Gynecol 2006, 195:354-359.

27. Gell JS: Mullerian anomalies. Semin Reprod Med 2003, 21:375-388

28. Sajjad Y: Development of the genital ducts and external genitalia in the early human embryo. J Obstet Gynaecol Res 2010, 36:929-937.

29. Kerecuk L, Schreuder MF, Woolf AS: Renal tract malformations: perspectives for nephrologists. Nat Clin Pract Nephrol 2008, 4:312-325.

30. Berry AC, Chantler C: Urogenital malformations and disease. Br Med Bull 1986, 42:181-186.

31. Thompson DP, Lynn HB: Genital anomalies associated with solitary kidney. Mayo Clin Proc 1966, 41:538-548.

32. Semmens JP: Congenital anomalies of female genital tract. Functional classification based on review of 56 personal cases and 500 reported cases. Obstet Gynecol 1962, 19:328-350.

doi:10.1186/1477-7827-10-57

Cite this article as: Oppelt et al:: Malformations in a cohort of 284 women with Mayer-Rokitansky-Küster-Hauser syndrome (MRKH).

Reproductive Biology and Endocrinology 2012 10:57.

\section{Submit your next manuscript to BioMed Central and take full advantage of:}

- Convenient online submission

- Thorough peer review

- No space constraints or color figure charges

- Immediate publication on acceptance

- Inclusion in PubMed, CAS, Scopus and Google Scholar

- Research which is freely available for redistribution 